\title{
30. SURFACE FEATURES OF QUARTZ SAND GRAINS FROM LEG 18 OF THE DEEP SEA DRILLING PROJECT
}

\author{
David H. Krinsley, Department of Earth and Environmental Sciences, Queens College, CUNY, Flushing, New York ${ }^{1}$
}

\begin{abstract}
The surface textures of five samples of quartz sand grains from the Aleutian Trench and Alaskan Abyssal Plain were examined by scanning electron microscopy. Solution and precipitation features were prominent, but all five samples contained evidence of previous glacial action. No differences were noted in surface features of grains from Upper Pleistocene and Middle Miocene samples taken from the same site, suggesting that most of the chemical action noted occurred in interstitial waters.
\end{abstract}

\section{INTRODUCTION}

The surface textures of quartz sand grains present in five samples taken from Sites 178, 180, and 181, off the south Alaska coast were examined by scanning electron microscopy. Attempts were made to determine which environmental forces acted upon the grains prior to deposition (Krinsley and Margolis, 1969; Margolis and Kennett, 1971) and the subsequent chemical histories of the grains. Both of these objectives were partially attained.

Practically all quartz grains examined were less than $500 \mu$ and most were between 75 and $300 \mu$ in diameter. The grains were picked by hand; the number examined in each sample is reported in Table 1. After being boiled in a 20 per cent $\mathrm{HCl}$ solution for ten minutes, they were washed several times in distilled water, mounted on specimen stubs and examined and photographed with the scanning electron microscope.

\section{RESULTS}

\section{Site 181}

There was essentially no difference between the two samples examined from Site 181. As reported in Table 1,

TABLE 1

\begin{tabular}{|c|c|c|c|c|}
\hline Sample & $\begin{array}{l}\text { No. Grains } \\
\text { Studied at } \\
\text { Each Site }\end{array}$ & $\begin{array}{c}\text { No. Grains } \\
\text { of Glacial } \\
\text { Origin }\end{array}$ & $\begin{array}{l}\text { Sample } \\
\text { Depth } \\
\text { Below } \\
\text { Sediment } \\
\text { Surface } \\
\text { (m) }\end{array}$ & Age \\
\hline $178-16-4(115-116)$ & 15 & 9 & 133 & U. Pleistocene \\
\hline $178-43-1(112-113)$ & 15 & 8 & 447 & M. Miocene \\
\hline $180-23-2(29-31)$ & 16 & 6 & 442 & Pleistocene \\
\hline $181-27-2(7-9)$ & 18 & 8 & 273 & Pleistocene? \\
\hline $181-27-2(12-14)$ & 8 & 4 & 273 & Pleistocene? \\
\hline
\end{tabular}

\footnotetext{
${ }^{1}$ Presently at the Sedgwick Museum, Cambridge, England.
}

twelve of the twenty-six grains from Site 181 are presumed to have originated in a glacial environment. Twenty-four of the grains have been greatly affected by chemical action; the other two have been moderately affected (see Krinsley and Margolis, 1969, for descriptions of glacial and chemical action on sand grain surfaces).

Both samples show movement within the sediment after deposition. Portions of cleavage plates on the surfaces of the sand grains have been gouged, flattened, and extended in one direction. Additionally, oriented, positive flutes are seen on some grains (Figure 1). These are long stringers of quartz or amorphous silica which have apparently been drawn out by movement within the sediment (perhaps pressure solution was operative here) and are superimposed on solution surfaces. Several grains (100 to $200 \mu$ in diameter) are almost completely broken through and this breakage seems to have taken place after a solutionprecipitation episode, as the grain surfaces are rounded, except for the breaks, which are jagged and irregular. It appears unlikely that these broken grains could have survived extensive transportation on the sea floor. Most of them have been strongly affected by chemical action (Figure 2). This intense degree of alteration has not been observed on grains from modern glaciers and, therefore, breakage probably occurred within the sediment. Thus the sequence of events is presumed to have been (a) transportation to the site, perhaps by ice rafting, (b) of solution and precipitation, and then (c) movement within the sediment.

The grains generally are covered with what is either amorphous silica (Siever and Scott, 1963) or quartz (McKenzie and Gees, 1971) precipitated from sea water; this precipitate forms knobby or bumpy projections on flat, conchoidal surfaces, but follows the upturned plate lithology on irregular surfaces (Krinsley and Margolis, 1969; Margolis and Krinsley, 1971). One of the grains in Sample 181-27-2(7-9) includes a flat face covered with what is evidently amorphous silica precipitated from solution; pieces of unidentified fossil debris are observed on the entire exposed grain surface (Figure 3). The outline of a bit of fossil material can easily be seen on the photomicrograph; other bits of debris, not as well preserved, are 


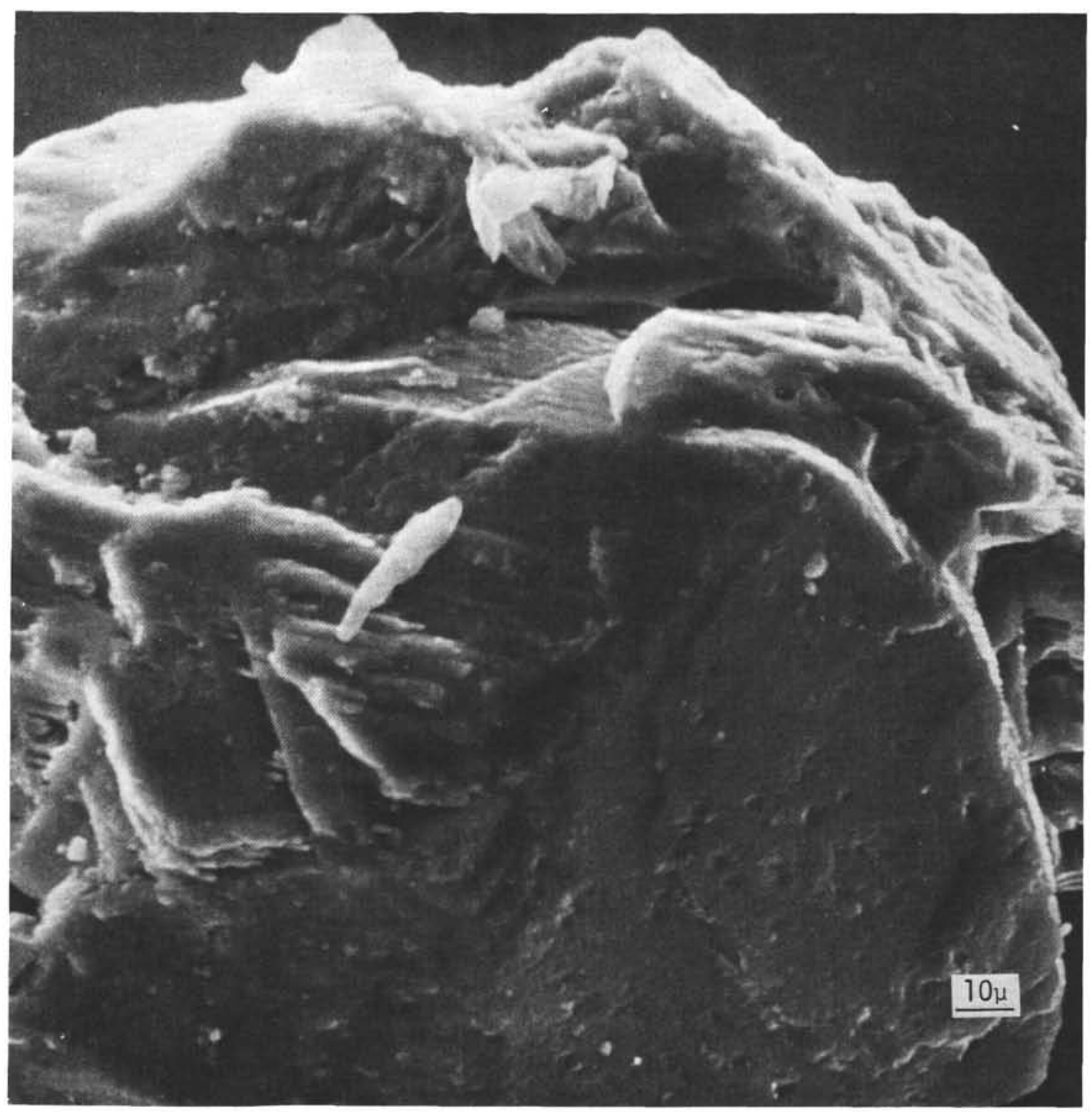

Figure 1. Portion of a quartz sand grain from Core 181-27-2(7-9). Lower right side of grain contains oriented etch patterns indicating solution. Oriented, positive flutes are seen in the middle and left center portions of the grain.

scattered irregularly over the grain surface. This occurrence suggests that amorphous silica, perhaps gellike in form, was deposited from seawater upon the grain surface. Thereupon, perhaps via sediment pressure before the gel hardened, pieces of fossil debris were pressed into the surface. The large amounts of silica in solution necessary for precipitation to occur may have originated with the dissolution of siliceous organisms composed of amorphous silica (Lewin, 1961) which were present in the surrounding sediment. Original report for Site 181 (this volume) suggests that the reason for lack of organisms may be dissolution.

Also present is evidence of chemical etching in the form of oriented V-shaped patterns (Figure 1). Commonly, solution and precipitation are found together, perhaps indicating more than one period of chemical action. However, more precipitation than solution is observed, indicating a net addition of silica to sand grain surfaces, again suggesting solution of siliceous organisms.

\section{Site 180}

Sample 180-23-2(29-31) includes six grains which are undoubtedly glacial in origin (Figure 4), being irregular with conchoidal breakage patterns and flat sides. Little solution and precipitation was observed on these grains. The other ten grains were so chemically altered that it was difficult to determine if they had ever shown original glacial features (Figures 5 and 6 ). The difference between the two types of grains is much more distinctive than between any of the grains examined at Site 181; this suggests two separate sources. The grains that were relatively unaffected by solution probably came directly from a terrestrial 


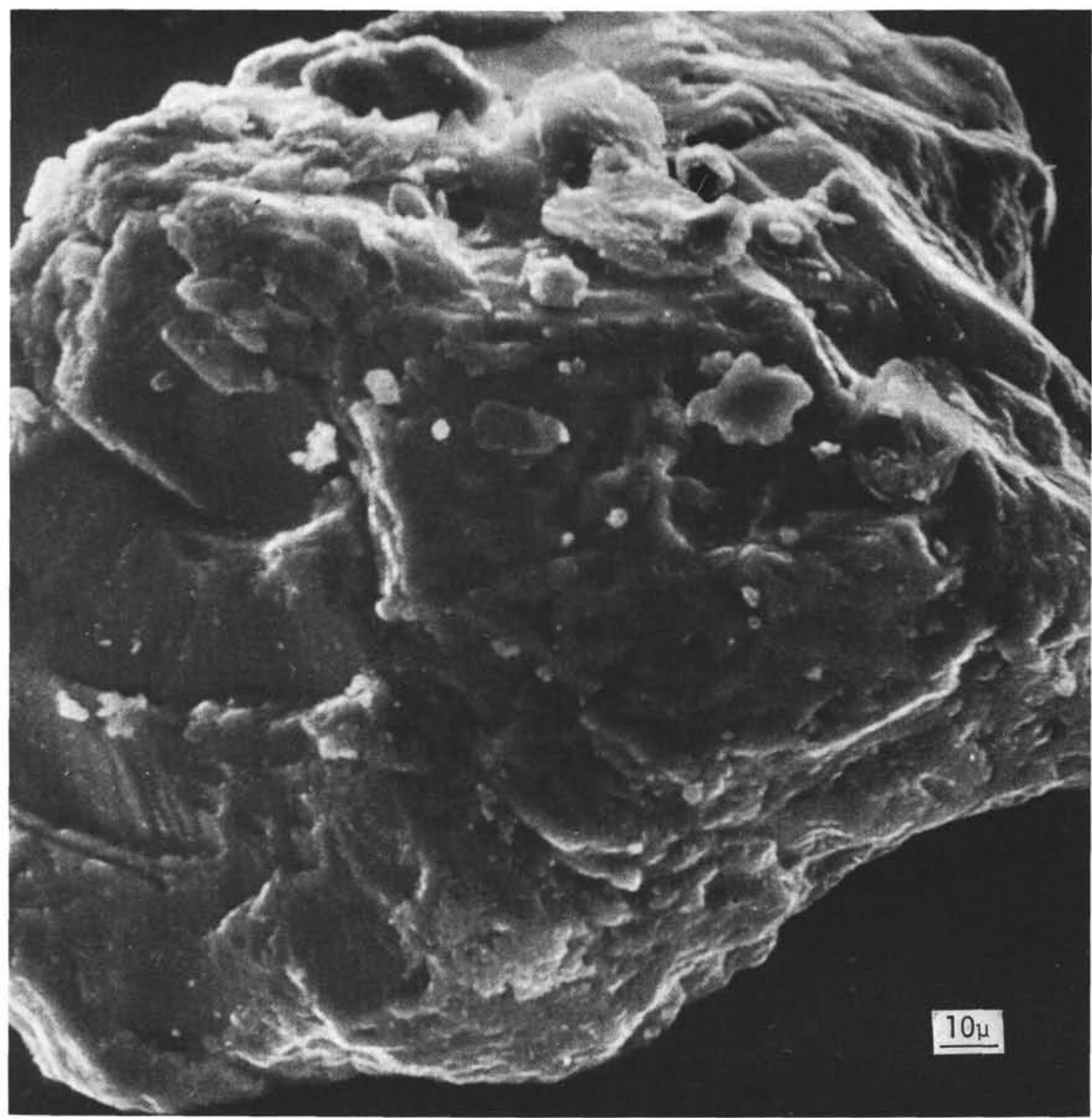

Figure 2. Grain from Core 181-27-1(12-14). Grain angularity has been much subdued by chemical action even though a few conchoidal breakage patterns can be observed on the left side of the photograph.

source, perhaps via ice rafting, while the other group may have been reworked a number of times from a marine source close by. If this hypothesis is correct, solution and reprecipitation were not very extensive at this site, suggesting rapid burial or chemical conditions not very amenable to solution and precipitation of silica.

\section{Site 178}

In sample 178-16-4(115-116) (Upper Pleistocene), nine of the fifteen grains were recognizably glacial, but eight out of the nine were extensively modified by solution and reprecipitation and only one was almost completely free of this condition. The other six grains were so covered with precipitated silica that their original environment could not be determined. It is possible that the one grain with very little chemical action represents material ice rafted to the site and that all other grains were reworked on the bottom and eventually carried to the site, regardless of their origin, as suggested for Site 180. Other hypotheses are also possible.

In sample 178-43-1(112-113) (Middle Miocene), all but two of the grains have been modified by a great deal of chemical action, but eight are probably of glacial origin. Grains from this sample do not appear to differ in terms of the kinds and amounts of solution and precipitation features from those grains studied at the same site of Upper Pleistocene age in sample 178-16-4(115-116) (Figures 7 and $8)$. This suggests that time is not an important factor in the diagenetic processes occurring at this site and that most of the chemical action took place in interstitial waters or perhaps immediately upon burial; the former is more likely. The presence and possible dissolution of siliceous organisms, along with the chemical composition of interstitial 


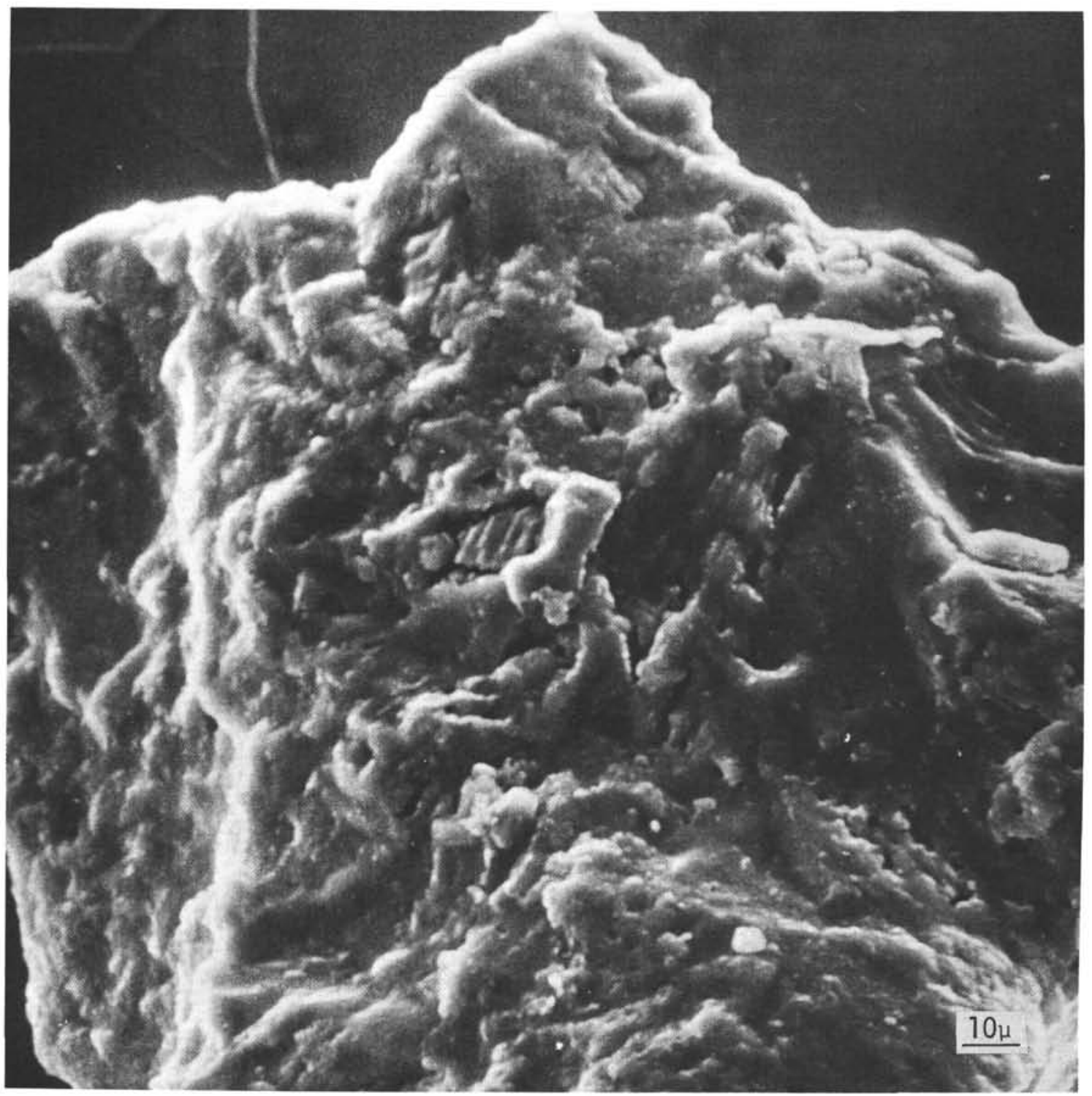

Figure 3. Grain from Core 181-27-1(7-9). Various bits of shell debris have been cemented to the sand grain surface; note particularly the corregated piece in the center of the photograph. In the upper right hand portion of the photograph, part of the original surface with a conchoidal breakage pattern is visible.

marine waters, appear to be two factors which are critical in the chemical evolution of sand grain surface textures in the marine environment.

\section{ACKNOWLEDGMENTS}

The author wishes to thank Dr. David Piper and Dr. Keith Tovey of the University of Cambridge and Professor Brian Funnell and Mrs. June Irvine of the University of East Anglia for assistance.

\section{REFERENCES}

Krinsley, D. and Margolis, S., 1969. A study of quartz sand grain surface textures with the scanning electron microscope. Trans. N.Y. Acad. Sci. 31, 457.
Lewin, J. C., 1961. The dissolution of silica from diatom walls. Geochim. et Cosmochim. Acta. 21, 182.

Margolis, S. and Kennett, J., 1971. Cenozoic paleoglacial history of Antarctica recorded in subantarctic deep-sea cores. Am. J. Sci. 271, 1.

Margolis, S. and Krinsley, D., 1971. Submicroscopic frosting on eolian and subaqueous quartz sand grains. Bull. Geol. Soc. Am. 82, 3395

McKenzie, F. and Gees, R., 1971. Quartz: Synthesis at earth-surface conditions. Science 173, 533.

Siever, R. and Scott, R., 1963. Organic geochemistry of silica. In Organic Geochemistry. Breger, I. (Ed.). Oxford (Pergamon Press). 579. 


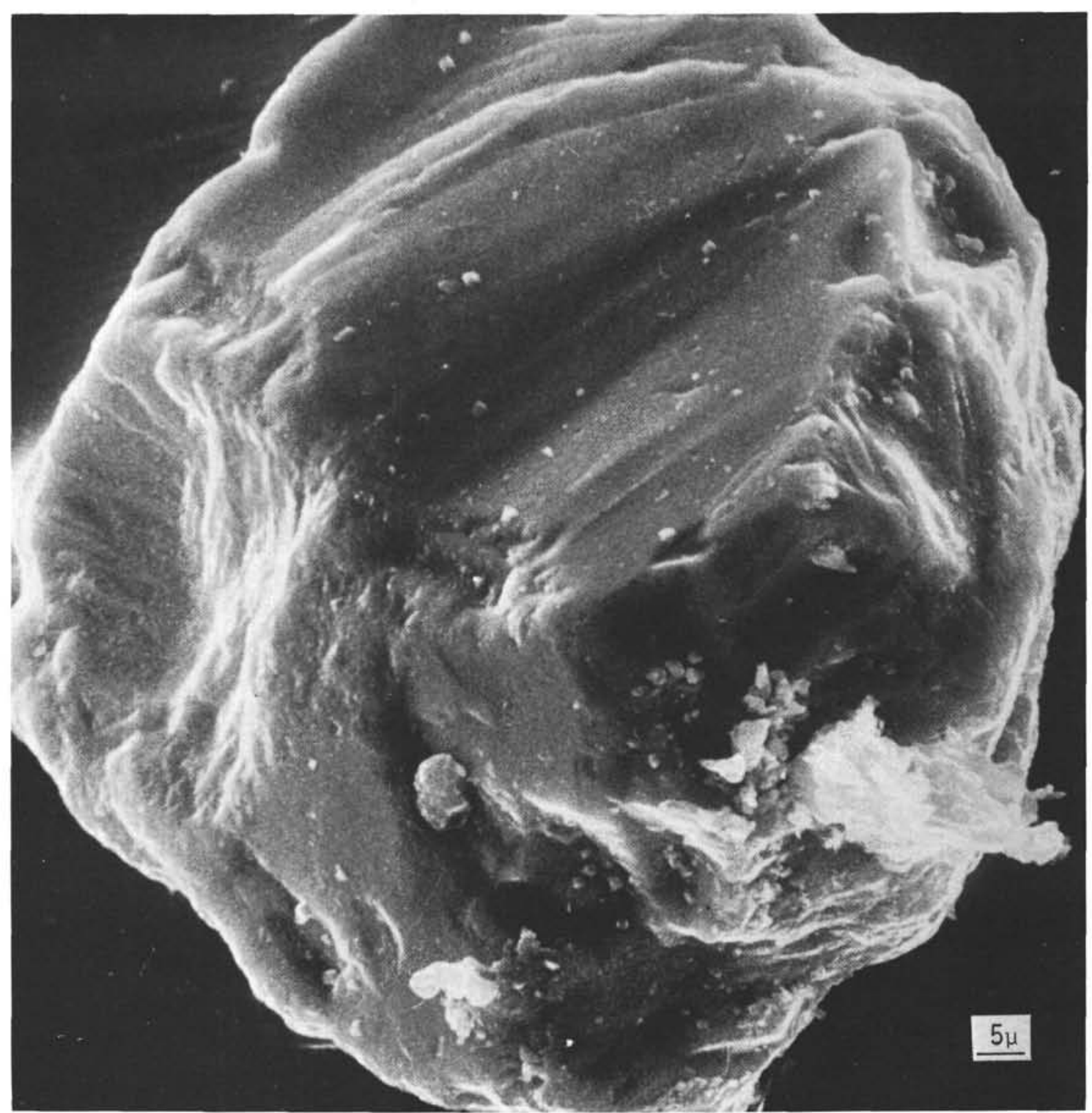

Figure 4. Grain from Core 180-23-2(29-31). Glacial features are prominent on this grain; a slight amount of rounding and smoothing, probably chemical should be noted. 


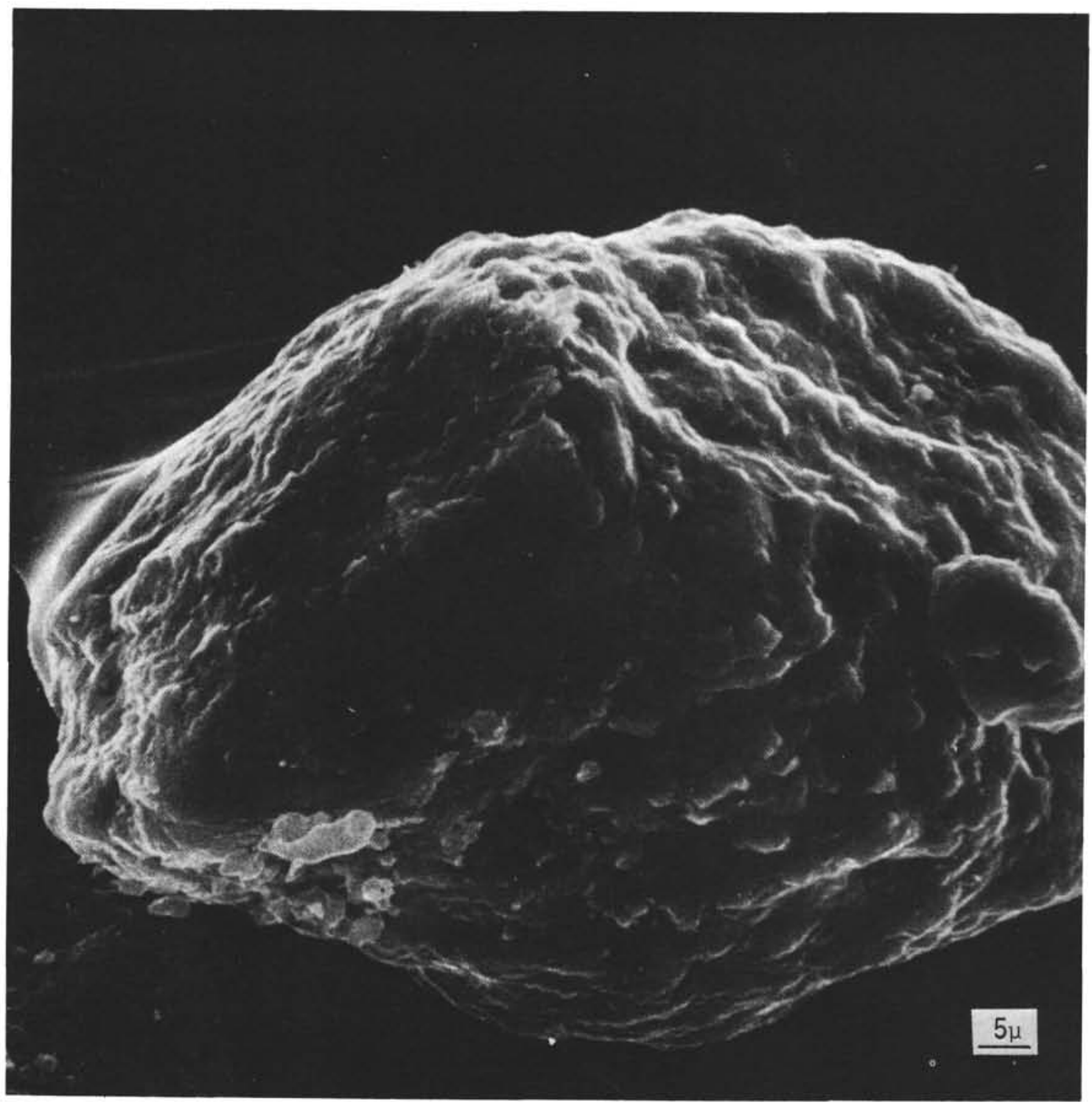

Figure 5. Grain from Core 180-23-2(29-31). Grain with surface almost completely altered chemically, probably due to silica solution and precipitation. Note the rounded, upturned oriented plates characteristic of chemical action on the bottom and left sides of the grain. The flat surface in the center of the photograph is bumpy and irregular, again the result of chemical action. 


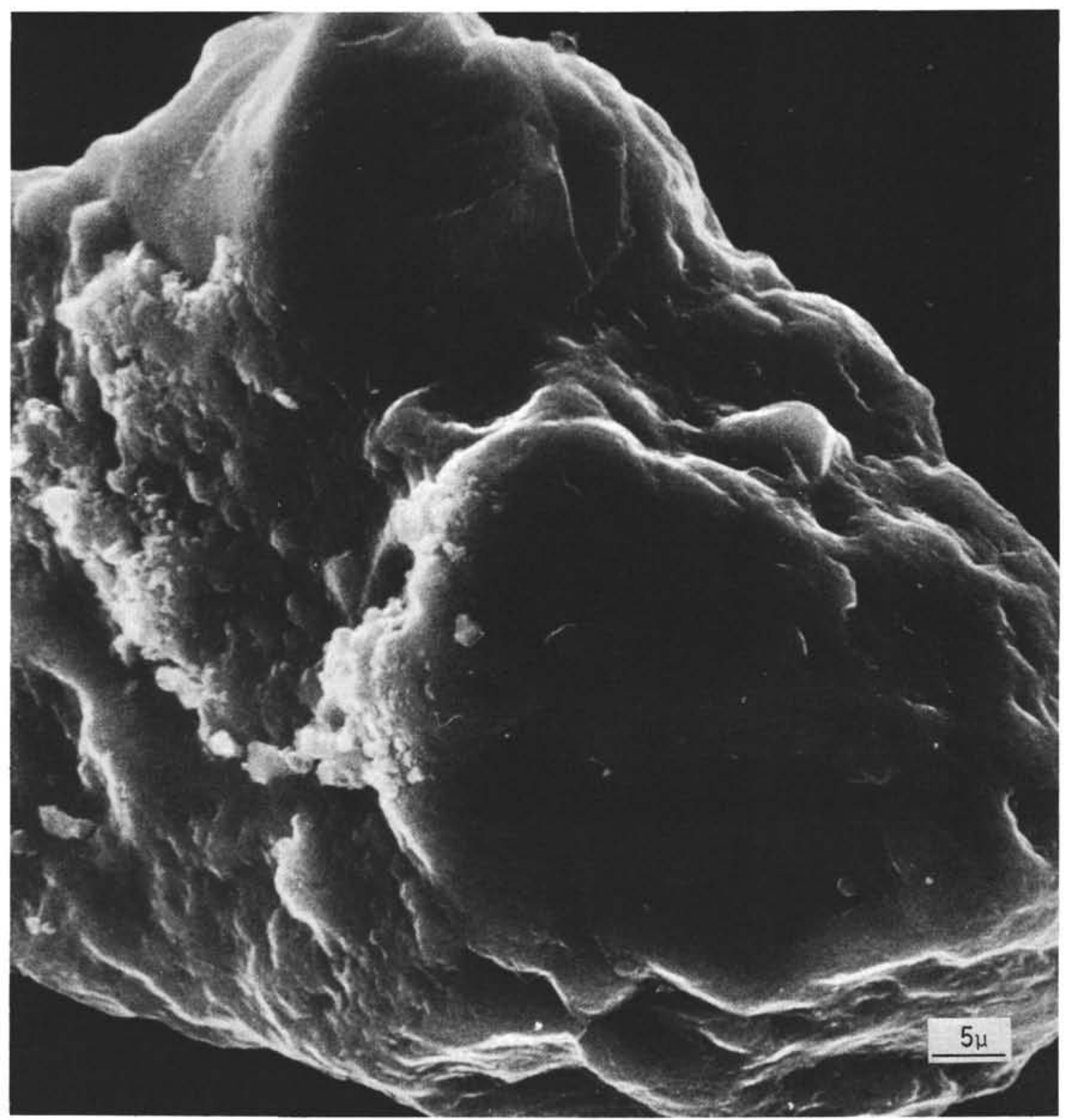

Figure 6. Grain from Core 180-23-2(29-31). Grain showing growth of silica in left central portion of the photograph, encroaching upon a conchoidal surface at the top, which has been smoothed, perhaps by an earlier period of chemical action. 


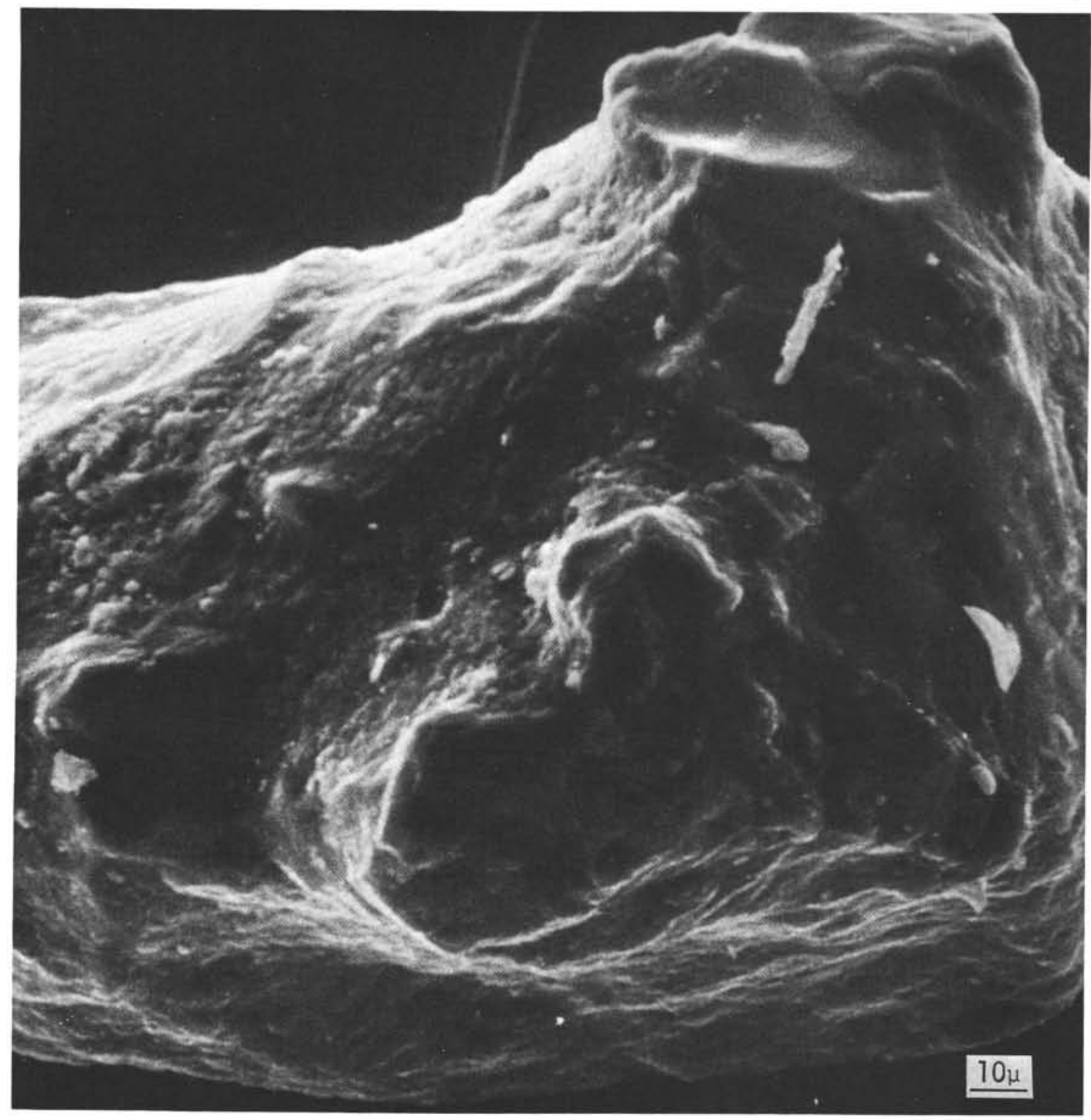

Figure 7. Grain from Core 178-16-4(115-116). Grain shows smoothing and rounding of flat surfaces and upturned cleavage plates, probably by silica solution and precipitation; this is characteristic of chemical action. (Upper Pleistocene). 


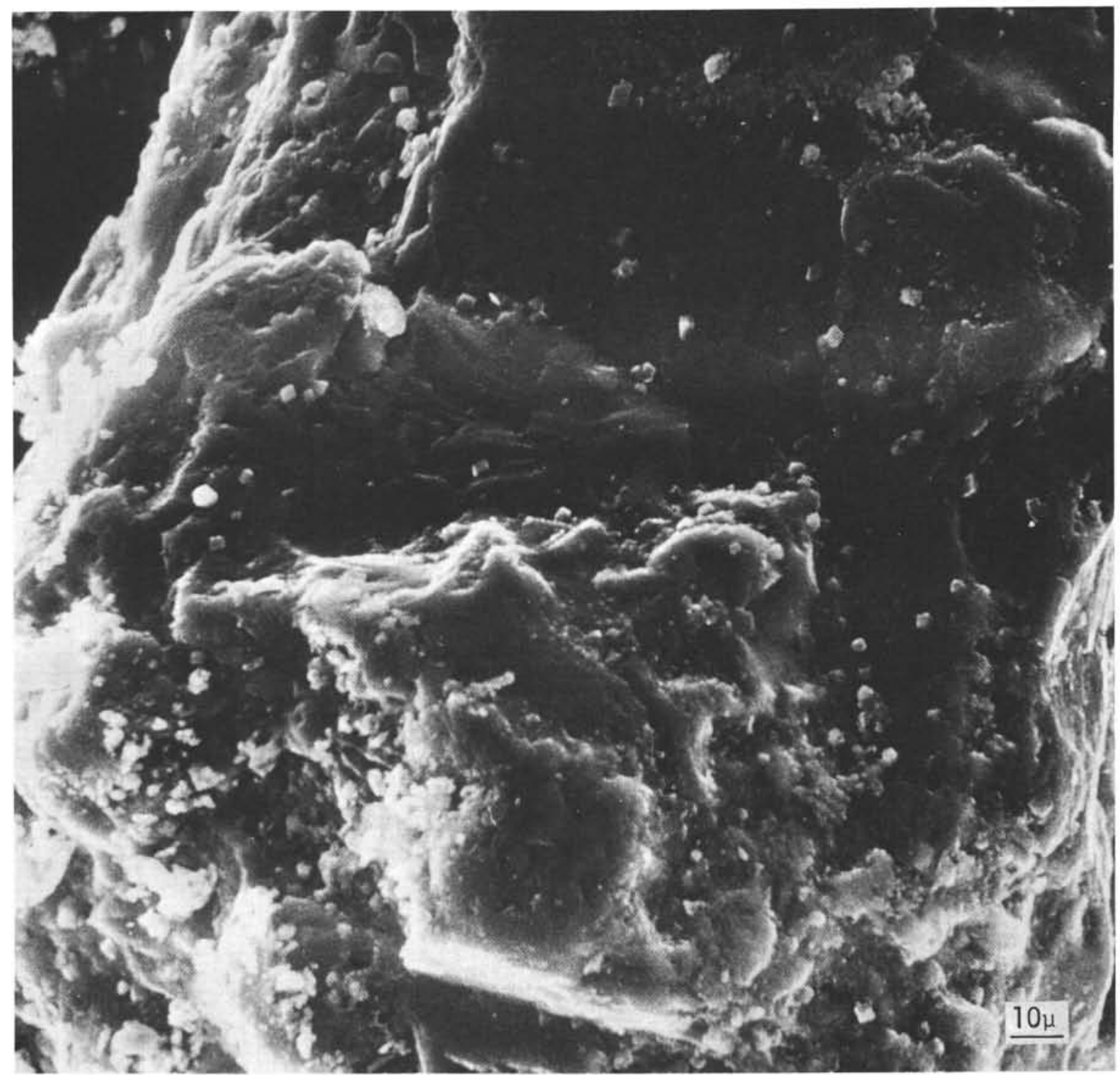

Figure 8. Grain from Core 178-43-1(112-113). Note that this grain and the preceding one came from the same core. The grain includes rounding of flat surfaces and upturned cleavage plates probably by silica solution and precipitation. This surface includes conchoidal breakage patterns which probably were impressed on the surface prior to chemical action. Thus the grain is not quite as altered as that in Figure 7. (Middle Miocene). 